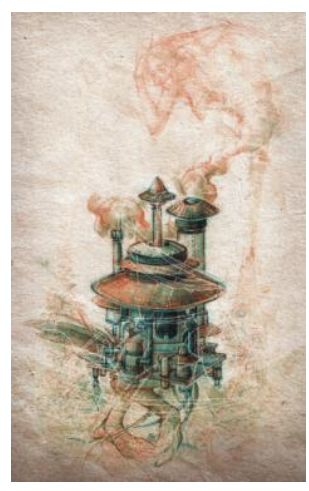

\title{
DOSSIÊ: $2^{\circ}$ Congresso de História da Ciência e da Técnica
}

\section{Ciência econômica e economia da cultura: Transferências e especificidades}

\author{
Ana Paula Nobile Toniol \\ Doutoranda em História Econômica \\ FFLCH - Universidade de São Paulo \\ nobile.anapaula@gmail.com
}

\author{
Sara Albieri $^{2}$ \\ Professora do Departamento de História \\ FFLCH - Universidade de São Paulo \\ sara@usp.br
}

Como citar este artigo: Toniol, A.P.N., Albieri, S. "Ciência econômica e economia da cultura: Transferências e especificidades", Intelligere, Revista de História Intelectual, nº7, p. 263-271. 2019. Disponível em $<$ http://revistas.usp.br/ revistaintelligere $>$. Acesso em dd $/ \mathrm{mm} /$ aaaa.

Resumo: A proposta de uma economia da cultura recorre à lógica econômica, seus conceitos e metodologia para uma análise econômica da indústria cultural, compreendendo: efeitos externos, investimentos a longo prazo, especificidade de remuneração, importância do subsidio público ou privado, aliados a um forte componente de incerteza. Ao transpor o valor econômico à cultura, tanto fomenta discussões sobre orçamentos públicos como envolve o setor corporativo nas questões culturais, criando metodologias para avaliação do impacto econômico da cultura na geração de riqueza e empregos Essa avaliação inclui: valor do capital cultural, participação no mercado, direitos de propriedade intelectual, justificativas para a interferência estatal no mercado, estimativa dos impactos dos acordos multilaterais nas relações sociais e na preservação das expressões culturais de um povo. A economia da cultura se utiliza das técnicas oferecidas pelo conhecimento econômico para defender a importância da cultura como geradora de crescimento econômico e seu potencial para o desenvolvimento socioeconômico.

Palavras-chave: ciência econômica, economia da cultura, políticas culturais.

\section{Economic Science and culture economics: transfers and specificities}

Abstract: The proposal of a cultural economics relies on the use of economic logic, its concepts and methodology, for an accurate analysis of the cultural

\footnotetext{
${ }^{1}$ Aluna de Pós Graduação em História Econômica na Faculdade de Filosofia, Letras e Ciências Humanas da Universidade de São Paulo. Tem experiência na área de administração, com ênfase em indústria e varejo de moda, organização e estudos para a indústria têxtil.

2 Professora titular da Universidade de São Paulo. Doutora em Filosofia pela mesma Universidade. Tem experiência na área de História, com ênfase em Teoria e Filosofia da História, Historia da Cultura, História Intelectual e das Ideias.
} 
industry, comprising : external effects, long-term investments, specificity of remuneration, importance of public or private subsidy, including a strong component of uncertainty. By transposing economic value to culture, it both fosters discussions about public budgets and engages the corporate sector in cultural issues, creating methodologies for assessing the economic impact of culture on the generation of wealth and jobs.Such assessments comprise value of cultural capital, market share, intellectual property, justification for state interference in the market, estimation of the impact of multilateral agreements on social relations and the preservations of cultural expressions of a people. Cultural economics imports the tools of economic knowledge to help support the relevance of culture as a generator of economic growth and its potential for socioeconomic development.

Keywords: economic science, culture economics, culture politics.

"La culture, plus on la consomme,
plus on a envie d'en consommer"
Francoise Benhamou (2012)

Introdução

A junção entre a ciência econômica e a cultura constitui um interessante exercício de reflexão acerca da história do pensamento econômico. Etimologicamente, o conceito de cultura é atribuído ao cultivo da terra e também se refere ao desenvolvimento intelectual, ao acúmulo de conhecimento que torna alguém "culto". Outro significado, pertence à uma abordagem antropológica, em que a palavra "cultura" engloba não só o conhecimento, mas artes, crenças, línguas, leis, valores, costumes, atitudes e visões de mundo. Raymond Williams descreve que "cultura" é uma das palavras mais complicadas da língua inglesa. Ele sugere que este último conceito de cultura foi introduzido no final do século XVIII por Herder que propunha uma concepção multilinear de cultura, ou seja, "específicas e variáveis culturas de diferentes nações e períodos, mas também de grupos sociais e econômicos" (Williams, 1976, p.79). Nesse sentido, a cultura passa a ser um "modo de vida", que inclui práticas e atividades culturais e uma não se sobrepõe a outra. Para Williams: 
"cultura é uma descrição de um modo particular de vida que exprime certos significados e valores, não só na arte e no saber, mas também nas instituições e no comportamento habitual" (1961, p.57).

Observar como a ciência econômica evoluiu e quais eram os interesses pela cultura por parte dos renomados economistas permitem estabelecer importantes balizas quanto à criação da economia da cultura. Com a expansão mercantilista, a ciência econômica tornou possível a discussão sobre valor de modo abstrato e sem julgamentos morais, pois as questões comerciais foram separadas da teologia em nome dos interesses do Estado (Wilk, 2007, p.41). A economia se desenvolve como a ciência responsável pela análise da produção, alocação e consumo de recursos (trabalho, dinheiro, matérias-primas, etc.), com o objetivo de estabelecer uma relação entre essas variáveis e propor a melhor solução para os objetivos traçados.

Segundo Adam Smith, os gastos com as artes inserem-se nas atividades de lazer e não tem como contribuir para a riqueza da nação. Smith considera a cultura como um trabalho improdutivo. Reconhece, no entanto, que a remuneração do artista reflete o custo do investimento que seu trabalho exige.

“[...] se o Estado encorajasse, isto é, se concedesse total liberdade a todos aqueles que, por seu próprio interesse, quisessem tentar divertir e entreter o povo, sem escândalo e sem indecência, por meio da pintura, da poesia, da música e da dança, por qualquer tipo de espetáculo e representação dramática, acabaria facilmente por dissipar, na maioria das pessoas, aquele humor sombrio e aquela predisposição à melancolia que constituem, quase sempre, o alimento da superstição e da angústia" (2010, Livro V, cap.1, seção 3).

Marshall escreveu em Principles of Economics: "É impossível avaliar objetos como os quadros dos mestres ou moedas raras; eles são únicos em seu gênero, não tem iguais e nem concorrentes; [...]. O preço de equilíbrio nas vendas desses objetos depende muitas vezes do acaso; no entanto, um espírito curioso poderia sentir algum prazer em empreender um estudo minucioso do fenômeno" (Marshall, 1997, p.319). Mais tarde, ele reconhece a "lei que institui que, quanto mais um indivíduo ouve música, mais aumenta seu gosto por ela", abrindo caminho, assim, para a análise dos consumos de arte que constituem uma exceção à teoria da diminuição da utilidade marginal (Benhamou, 2007, p.16). 
Keynes, foi um grande colecionador de arte e chegou a persuadir o Chanceler do Tesouro para adquirir coleções particulares. Também atuou como defensor do Council for Music and the Arts, cujo objetivo era garantir o sustento dos artistas durante a II Guerra Mundial e foi um dos grandes pivôs na formação do Arts Council England, instituição pública voltada ao financiamento das artes na Inglaterra.

Ainda que esses cientistas não tenham realizado propriamente uma análise econômica do setor cultural, seus pensamentos, conceitos e teorias contribuíram para que gradativamente a base da economia da cultura tenha se constituído. A teoria neoclássica foi responsável por não mais diferenciar as atividades produtivas e improdutivas. $O$ valor de um bem passou a ser mensurado "em termos da utilidade que proporciona a quem o adquire ou o consome" (Reis, 2007, p. 29).

\section{A economia da cultura e o capital cultural - origem e desenvolvimento}

Precedente à economia da cultura, o conceito de "indústria cultural" foi firmado pelo filósofo alemão Theodor Adorno e desenvolvido pelos teóricos da Escola de Frankfurt. Para Adorno, o conceito analítico de indústria cultural mostra que o consumidor "não é sujeito dessa indústria, mas seu objeto". E ainda, favorece a dependência e servidão dos homens, na medida em que "impede a formação de indivíduos autônomos, independentes, capazes de julgar e de decidir conscientemente(Adorno, 1987, p.285-288). Mas as primeiras inclinações em direção à análise econômica da cultura, vêm da Alemanha, no início do século XX, em especial a partir do artigo " $A$ arte e a economia", publicado em 1910 na revista acadêmica alemã "Volkwirtschafliche Blatter".

Nas décadas seguintes surgiram estudos que abriram os caminhos da futura economia da cultura. Conhecida por incentivar e fomentar projetos sociais e culturais, e diante de um quadro de custos crescentes das produções e falta de condições financeiras para as operações, a Fundação Ford contratou, em 1965, a consultoria dos economistas William Baulmol e William Bowen para desenvolver a análise do setor de teatros e apresentações ao vivo na Broadway. 
Com o estudo "Performing Arts: the economic dilemma", Baulmol e Bowen, se tornaram precursores da economia da cultura. Este estudo, cuja abordagem procura elencar argumentos para a ação pública no mercado de artes (CNPC, 2012), defendia que as produções da Broadway usavam o trabalho de modo a gerar ganhos de produtividade, ao contrário de um setor tipicamente industrial, que, segundo a sua tese, se utiliza da tecnologia para obter ganhos e redução de custos. Posteriormente, com o uso cada vez mais crescente da tecnologia, muitas ressalvas foram feitas a este estudo.

Outros estudos, como o de Gary Becker sobre o consumo de bens, os de Alan Peacock e da escola Public Choice procuravam restabelecer os vínculos com os paradigmas tradicionais da economia política e contradiziam os trabalhos de Baulmol e Bowen, que defendiam a dependência de subsidio público às artes. Em 1976, Mark Blug propõe que as economias da arte constituem uma espécie de "terreno de experimentação da pertinência dos conceitos econômicos fundamentais" (Benhamou, 2007, p.17-18). Em 1988, na Inglaterra, um estudo de Myerscough, The Economic Importance of the Arts in Britain, colocou em evidência o setor cultural da Grã-Bretanha, com a cifra de 10 bilhões de euros anuais e cerca de 500 mil empregos no setor (Reis, 2007,p.16). A partir da década de 1990, a economia da cultura é reconhecida institucionalmente e a American Economic Association a inclui em sua classificação de disciplinas econômicas, juntamente com uma publicação de David Throsby no Journal of Economic Literature.

Alguns fatores contribuíram para este reconhecimento institucional: a tendência para gerar fluxo de renda e empregos, necessidade de avaliações das decisões culturais e evolução da economia política para novos campos.

Assim, a cultura se instituiu como um setor que gera empregos. Suas relações entre indivíduos, grupos e empresas são peculiares e internamente diferenciam-se de outros setores. Com caráter instrumental, a economia transpõe a serviço da cultura, seus instrumentos como planejamento, eficiência, eficácia, estudo de comportamento humano e dos agentes de mercado (Reis, 2007, p.1-4). A economia analisa as relações entre oferta, distribuição e demandas e identifica possíveis falhas de mercado, com o objetivo de 
potencializar recursos, agentes e estruturas. Com efeito, a economia da cultura se refere ao uso da lógica econômica e de sua metodologia no campo cultural.

Assim, a base da economia da cultura se constituiu, estendendo seus métodos e conceitos que serviriam de base para uma análise econômica da indústria cultural, compreendendo: efeitos externos, investimentos a longo prazo, especificidade de remuneração, envolvendo sobretudo, um forte elemento de incerteza, bem como a importância do subsidio público ou privado.

Do mesmo modo, que a indústria cultural se desenvolveu, o conceito de capital cultural também foi criado. Bourdieu (1979), o define como os atributos intelectuais oriundos tanto do ambiente familiar como também os produzidos pelo ambiente acadêmico. David Throsby utiliza o termo fazendo referência ao patrimônio cultural, como "capital cultural tangível e intangível, não somente pinturas, construções e monumentos mas também a literatura e música". Para ele, os economistas podem "contribuir ajudando a transformar o conceito de sustentabilidade como aplicado à cultura em uma realidade operacional” (Word Bank, 2000, p.40).

\section{Transferências e Especificidades}

Ao transpor o valor econômico à cultura, a economia da cultura é capaz de fomentar discussões sobre orçamentos públicos e envolver o setor corporativo nas questões culturais, e quando se utiliza de metodologias de avaliação do impacto econômico da cultura na geração de riqueza e empregos: valor do capital cultural, participação no mercado, direitos de propriedade intelectual, justificativas para a interferência estatal no mercado, estimativa dos impactos dos acordos multilaterais nas relações sociais e na preservação das expressões culturais de um povo. A economia da cultura se utiliza dos instrumentos e técnicas da ciência econômica para validar a importância da cultura como geradora de crescimento econômico e seu potencial para o desenvolvimento socioeconômico.

Assim, podemos utilizar a mesma definição de economia da cultura aplicada pelo Journal of Cultural Economy: 
Economia Cultural é a aplicação da análise econômica a todas as artes criativas e cênicas, às industrias patrimoniais e culturais, sejam de capital aberto ou fechado. Ela se preocupa com a organização econômica do setor cultural e com o comportamento dos produtores, consumidores e governos nesse setor. $O$ tema inclui uma variedade de abordagens, de correntes principais e radicais, neoclássicas, de economia do bem-estar, de política pública e de economia institucional.

Sendo uma disciplina nova, a economia da cultura desafia alguns pressupostos básicos da teoria econômica e exige adaptações. Uma das primeiras contestações diz respeito à lei das utilidades marginais decrescentes, segundo a qual a utilidade marginal proporcionada pelo consumo diminui progressivamente, conforme se consomem novas unidades. Ex: Tomar sorvete é muito prazeroso mas o segundo não é tão apreciado quanto o primeiro. Já no campo cultural, como o próprio Marshall sinalizou, "quanto mais boa música uma pessoa ouvir, mais provável é que seu gosto por ela aumentará". No campo cultural, o consumo da cultura fomenta a formação do hábito. Quanto mais produtos e serviços culturais uma pessoa consumir, mais gosto terá por esse consumo.

O segundo aspecto é a intangibilidade, e mais ainda, a valoração da criatividade. $\mathrm{O}$ arsenal de instrumentos econômicos é adequado para mensurar produtos e algumas formas de serviços porém não apreende o valor total do intangível. É preciso criar uma metodologia que contemple o valor dos intangíveis culturais. Como mensurar o valor de uma editora e sua carteira de autores? Como precificar um quadro? Qual o recurso necessário para manter uma instituição cultural? Qual o valor de uma tecnologia cultural? São questões que devem ser respondidas não só como reconhecimento econômico aos criadores e sustentar as ações de política pública, como também eliminar gargalos de financiamento do setor cultural.

Enquanto o preço de um bem cultural é fixado pelo mercado e para se concretizar necessita de ao menos um comprador e um vendedor, o valor atribuído a ele é altamente subjetivo. E ainda, se esse bem cultural for público, o responsável pelo reconhecimento do valor é o governo.

Para Throsby (2001), além do valor econômico, o bem cultural possui o valor cultural que pode ser classificado em estético, social, espiritual, político. O valor estético é atribuído ao "conjunto de percepções de uma sociedade", ou seja, como a sociedade vê esteticamente um bem cultural. $\mathrm{O}$ valor social reflete 
a identidade da sociedade e o que este bem representa. $\mathrm{O}$ valor da existência resulta na sociedade ter conhecimento que um determinado bem cultural existe. $\mathrm{O}$ valor espiritual transmite a ideia do quão sagrado um bem cultural de ordem religiosa pode ser.

Enfatizando a questão do valor político, o governo possui a prerrogativa de decidir investir em um bem cultural público por diversas razões como aumento da qualidade de vida, valorização da diversidade, construção da identidade, criação de laços sociais, preservação da memória. $\mathrm{O}$ foco deverá ser o beneficio para a sociedade e cabe aos gestores públicos em considerar esses valores econômicos e culturais para fomentar seus investimentos.

\section{Conclusão}

A economia da cultura é fortemente marcada por um caráter dual. Concomitantemente transmite uma mensagem simbólica e possui grande representatividade econômica.

Traçar uma política cultural requer o uso da metodologia e dos instrumentos da ciência econômica a fim de construir uma base histórica para análise desses dados. A economia da cultura deve ser capaz de avaliar se os recursos são suficientes e se há uma aplicação adequada.

Como ciência, a economia da cultura precisa responder questões que derivam diretamente da ciência econômica. É necessário como premissa saber quais recursos são necessários no setor cultural dentre ministérios, secretarias, órgãos públicos; bem como, quais são os investimentos do setor privado e terceiro setor. E, essencialmente, como esses recursos serão empregados.

A eficácia da economia da cultura é mensurada quando atende as demandas da sociedade, gera valor, empregos e qualidade de vida. Estes devem ser resultados práticos desses investimentos. Não basta uma captação e investimento de recursos. É primordial uma análise dos efeitos dos programas e ações culturais. Isso só será possível com a utilização das técnicas oferecidas pelo conhecimento econômico.

\section{Referências bibliográficas}

ADORNO, Theodor. A indústria cultural. In: COHN, Gabriel. (org.). Comunicação e indústria cultural. São Paulo: T. A. Queiroz, 2007. 
BENHAMOU, Françoise. A economia da cultura. Tradução: Geraldo Gerson de Souza - São Paulo. Ateliê. 2007.

- "La culture, plus on la consomme, plus on a envie d'en consommer" Le

Monde, 09 de mar de 2012. Disponível em: < http://www.lemonde.fr/culture/article/2012/03/09/la-culture-plus-on-laconsomme-plus-on-a-envie-d-en-consommer 1655773 3246.html> (acesso em 03/10/2015).

BOURDIEU, Pierre. La distinction - critique sociale du jugement. Paris. Les Éditions de Minuit, 1979.

Instituto das Indústrias Criativas e pelo Conselho Nacional de Políticas Culturais (CNPC), Secretaria Executiva e a Secretaria de Políticas Culturais do Ministério da Cultura. Economia e Cultura da Moda no Brasil. 2012.

Relatório de economia criativa 2010 : economia criativa, uma opção de desenvolvimento. - Brasília : Secretaria da Economia Criativa/Minc ; São Paulo : Itaú Cultural, 2012. Disponível em http://unctad.org/pt/docs/ditctab20103 pt.pdf. Acesso em: 20 mar. 2018

MARSHALL, Alfred. Principles of Economics, Amherst, N.Y. Prometheus Books, 1997.

REIS, Ana Carla Fonseca. Economia da cultura e Desenvolvimento sustentável: o caleidoscópio da cultura. Barueri: Manole, 1997.

SMITH, Adam. A riqueza das nações. São Paulo, Martins Fontes, 2003.

THROSBY, David. "The Production and Consumption of the Arts: A View of Culture Economics”, Journal of Economic Literature, 32: 1-29, 1994.

2001.

Economics and Culture. Cambridge, Cambridge University Press,

WILLIAMS, Raymond. The Long Revolution, Harmondsworth: Penguin Pelican, 1961. .Keywords, Glasgow: Fontana, 1976.

WILK, Richard R., Economies and Cultures - Foundations of economic anthropology, 2007.

WORLD BANK "Culture Counts - financing, resources and the economics of culture in sustainable development", 2000. Disponível em http://documents.worldbank.org/curated/en/302131468739317900/pdf/mul ti-page.pdf Acesso em 01/03/2019. 